\title{
Global Warming Effect for Migration Route of Japanese Chum Salmon
}

\author{
Masahide Kaeriyama ${ }^{1}$ and Yusuke Urabe ${ }^{2}$ \\ ${ }^{1}$ Arctic Research Center, Hokkaido University, N21 W11, Kita-ku, Sapporo, Japan 001-0021 \\ ${ }^{2}$ Ministry of Education, Culture, Sports, Science and Technology, 3-2-2 Kasumigaseki, Chiyoda-ku, Tokyo, Japan \\ 100-8959
}

Keywords: Japanese chum salmon, global warming effect, migration route, COBE-SST, NOAA-NCEP Database

\section{Introduction}

Since the late 1990s, population size and survival of Japanese chum salmon (Oncorhynchus keta) have indicated a decreasing trend. Especially the population size of salmon returning to Hokkaido in 2016 and 2017, which were the minimum levels since 1990 . However, it was predicted in the early 2000s that their population size in 2010 might become half of the maximum because of the new climate regime-shift since the end of the last century (Kaeriyama 2004, Kaeriyama et al. 2014). We also predicted the potential marine distribution of chum salmon in the North Pacific Ocean, the Bering Sea and the Chukchi Sea based on the SRES-A1B scenario in the Fourth Assessment Report of the IPCC (Kaeriyama 2008): 1) a northward shift in the distribution of chum salmon to the Chukchi Sea, and 2) loss of their migration route connecting Hokkaido with the Okhotsk Sea due to a thermal impediment.

Juvenile chum salmon remain in the coastal sea during the spring season (April-June) and migrate offshore at post-fingerling stage (average $10 \mathrm{~cm}$, range $8-12 \mathrm{~cm}$ in fork length) in Japan. This offshore migration is usually preceded by larger individuals having the higher growth rate and forage more actively on prey than others (Kaeriyama 1986; Kaeriyama and Ueda 1998). Juvenile chum salmon originating from distant sources tended to grow faster than those from more proximal sources, likely contributing to larger body size in the former. Larger juvenile (>90 $\mathrm{mm}$ in fork length) tended to have higher growth rate than smaller fish (Honda et al. 2017). Namely, by the end of June, Japanese juvenile chum salmon will migrate from coastal seas around Japan to the Okhotsk Sea at the developmental stage of the post-fingerling.

The distribution of juvenile salmon along their migration trajectory may be affected by physiological conditions such as body size and environmental factors such as water temperature, ocean currents, food availability (zooplankton biomass), etc. (Urawa et al. 2016). Japanese juvenile chum salmon were previously distributed during summer and autumn periods (from the mid-July to the November) in the Okhotsk Sea (Ueno and Ishida. 1998; Urawa 2015).

In the recent past, Chistyakova and Bugaev (2016) reported the distribution of juvenile pink and chum salmon with otolith marking released from hatcheries of Japan and Russia in the Okhotsk Sea in the fall (SeptemberNovember) of 2011-2014. Juvenile chum salmon were distributed latitude $47-57^{\circ} \mathrm{N}$ and longitude $146-156^{\circ} \mathrm{W}$, within their range. Their migration route was affected by the Okhotsk Sea Gyre. In July, in the Sea of Okhotsk coastal waters off South Sakhalin, the length and weight of most juvenile chum salmon of Japanese origin exceed 10 $\mathrm{cm}$ and $10 \mathrm{~g}$ (Shubin and Akinicheva 2016).

We addressed the potential progress of the global warming effects on Japanese chum salmon at the present moment in this paper.

\section{Data and Methods}

Sea surface temperature (SST) in the North Pacific Ocean, the Okhotsk Sea, the Bering Sea, and the Chukchi Sea was obtained via objective analysis using "COBE-SST" (Ishii et al. 2005) in the Japan Meteorological Agency (JMA) and the NOAA NCEP Database in the Earth System Research Laboratory (https://www.esrl.noaa.gov/psd/data/timeseries/). To evaluate distribution area of chum salmon, we used their optimum temperature $\left(8-12^{\circ} \mathrm{C}\right)$ and adaptable temperature $\left(5-12^{\circ} \mathrm{C}\right)$ based on growth rate, feeding behavior and catch per unit effort (CPUE) as population density (Kaeriyama 2004). We analyzed scales of female adult chum salmon at age 4 returning to the Tsugaruishi River during 1996-2017 in order to evaluate the growth backcalculation.

\section{Temporal change in return of Japanese chum salmon}

Since the late 1990s, the population size of Japanese chum salmon showed decreasing trends. In the last 4 years, the population size did not link with the PDO despite the linkage between it and PDO in the other years (Fig. 
1). The population size of Iwate chum salmon similarly showed decreasing trends since the late 1990s (Fig. 2a). Annual changes in anomalies of estimated fork lengths at the offshore migration and the age 1 generally synchronized with the population size except for 2013 and 2014 ocean entry years, the body size at the age 1 extremely decreased (Fig. 2b). The body size at the age 1 had a higher correlation with the population size than it at the offshore migration (Fig. 2c).

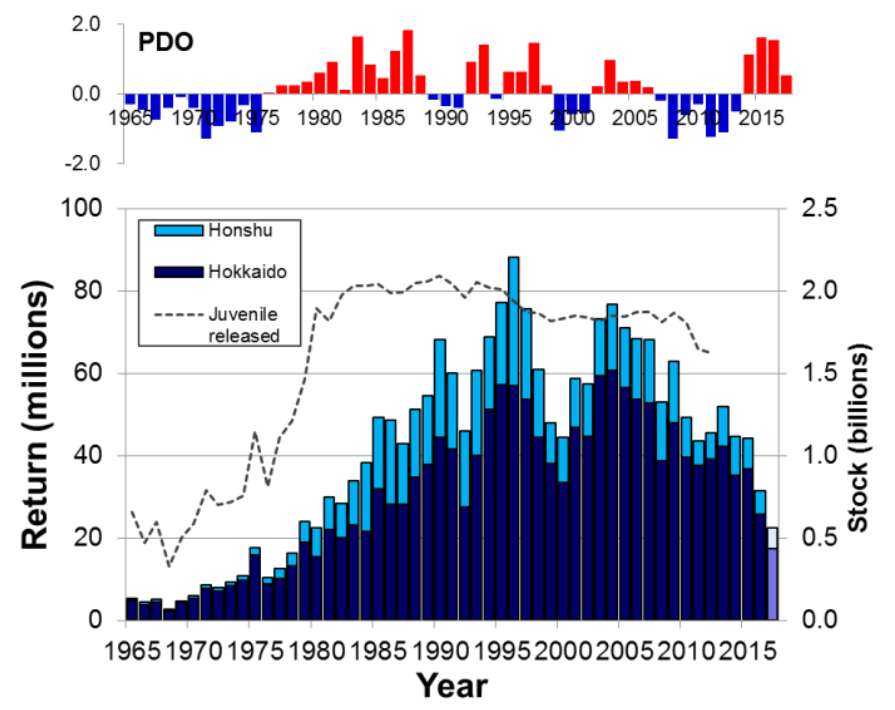

Fig. 1. Temporal changes in population size of Japanese chum salmon and PDO (1965-2017).
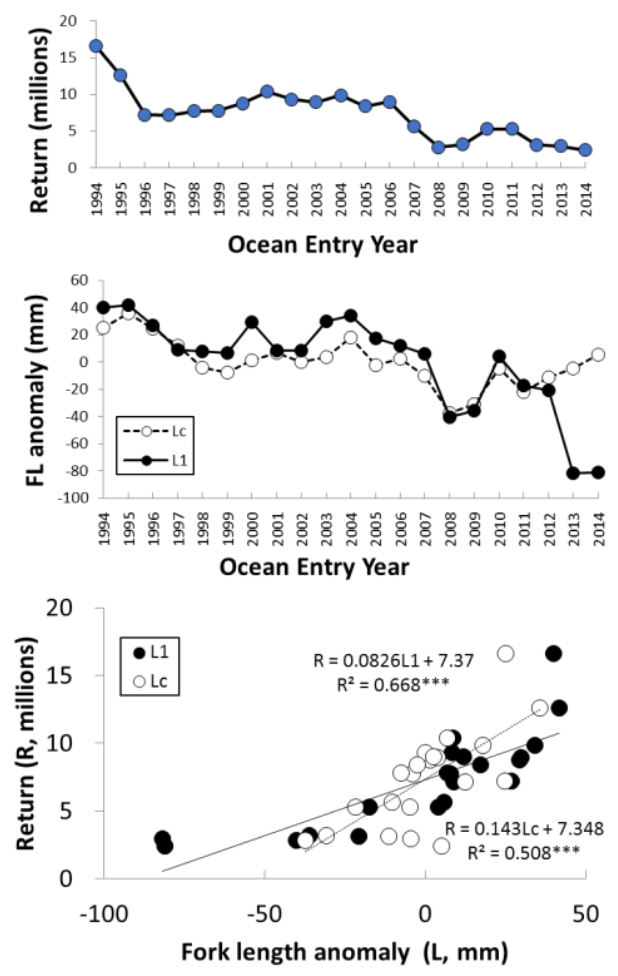

Fig. 2. Temporal changes in abundance (Fig. 2a), body size at the offshore migration and the age 1 for chum salmon in the Iwate Prefecture (Fig. 2b), and the relationship body size and return for chum salmon in the Iwate Prefecture. 
Since the 1990s, the resident duration (days of adaptable temperature) of juvenile in the coast decreased through time, and the relationship between the resident duration and the survival of chum salmon in the Northern Japan Sea $\left(R^{2}=0.396^{*}\right)$ and Sanriku $\left(R^{2}=0.256^{*}\right)$ areas showed a significant positive correlation despite no correlation in the other areas (Fig. 3).

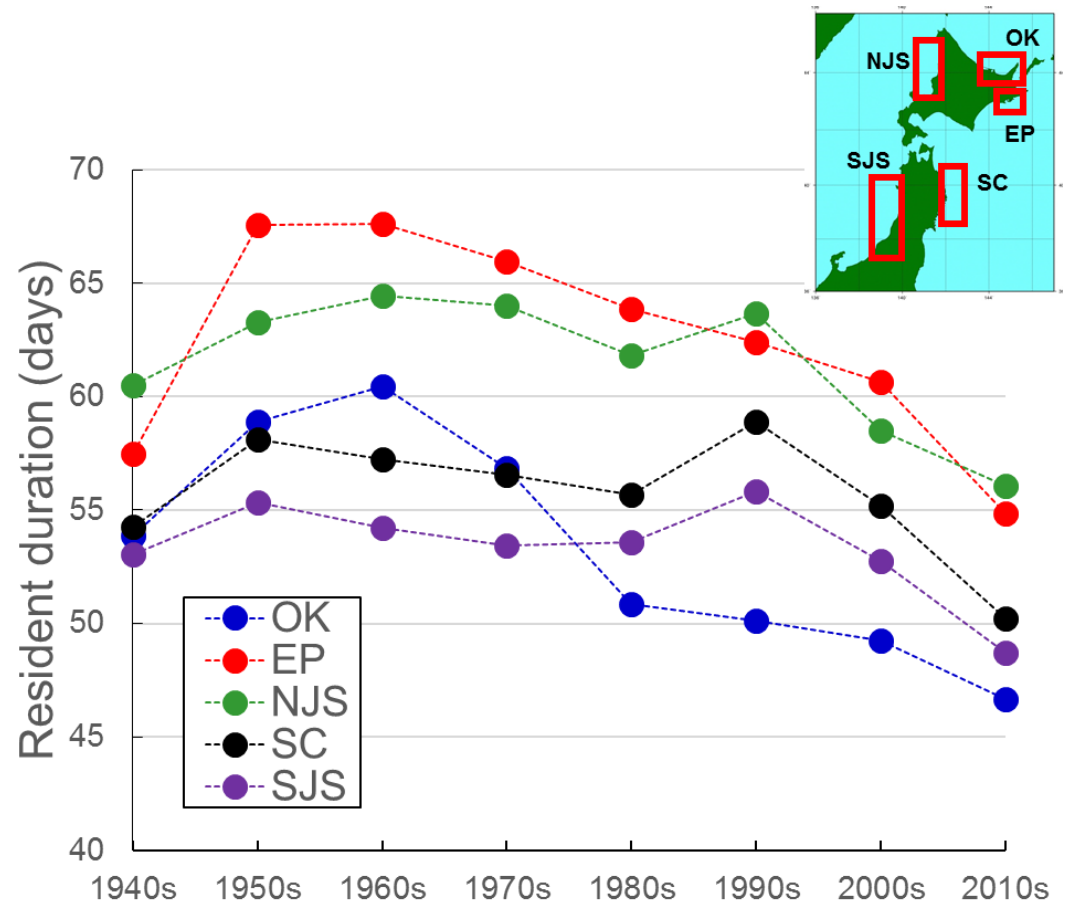

Fig. 3. Temporal changes in resident duration for juvenile chum salmon in coastal sea around Japan. OK:

Okhotsk Sea Coast, EP: Eastern Pacific Coast, NJS: Northern Japan Sea Coast, SC: Sanriku Coast, SJS: Southern Japan Sea Coast.

Japanese juvenile chum salmon have missed the migration route to the Okhotsk Sea since the 2010s

Based on the COBE-SST database (Ishii et al. 2005) and Kaeriyama (2008), we evaluated the change in the area of adaptable temperature (AAT) for chum salmon in August of 2005 and 2017 in the North Pacific Ocean and the Okhotsk Sea (Fig. 4). The AAT in 2017 markedly decreased in the Okhotsk Sea and the Gulf of Alaska but increased in the Chukchi Sea. This indicates that the global warming will progress to affect the distribution area of chum salmon in the North Pacific Ocean.

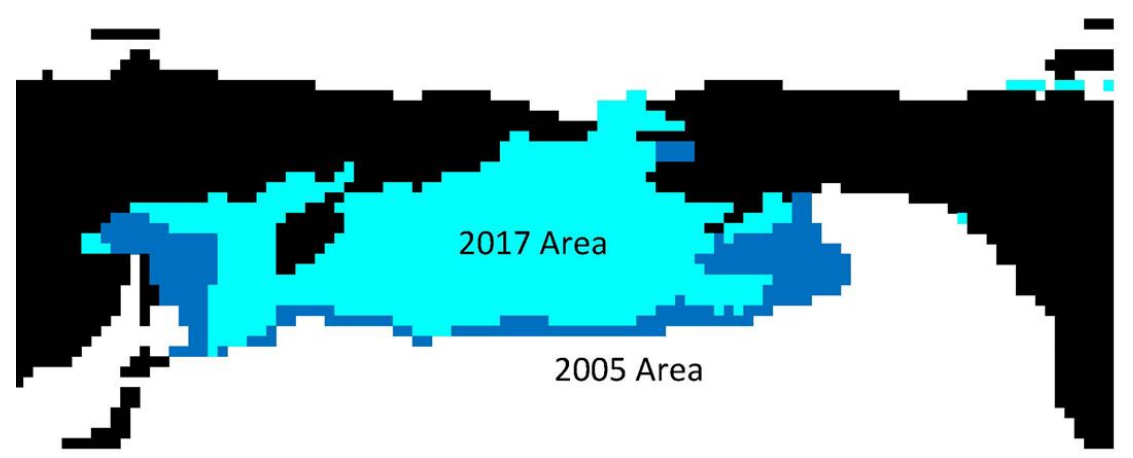

Fig. 4. Changes in the area of adaptable temperature (AT) for chum salmon in August of 2005 (匹) and 2017 (घ) in the North Pacific Ocean. 


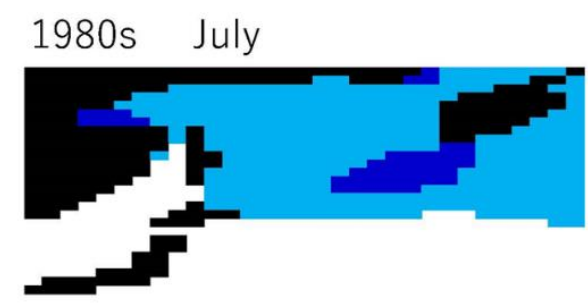

1990s July

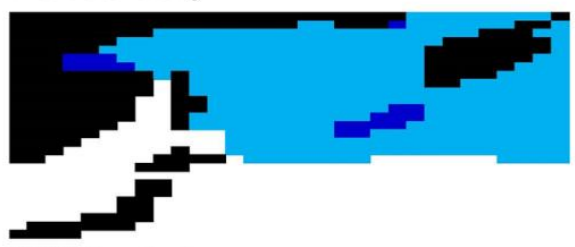

2000s July

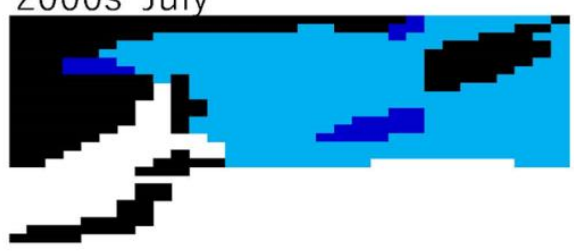

2010s July

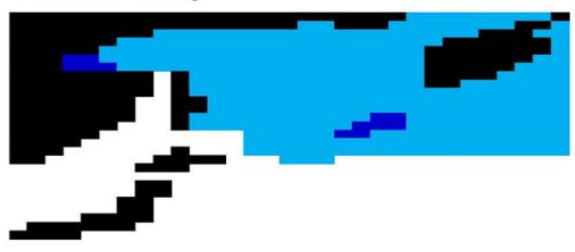

Fig. 5. Temporal changes in areas of adaptable and optimum temperatures in July in the Okhotsk Sea.

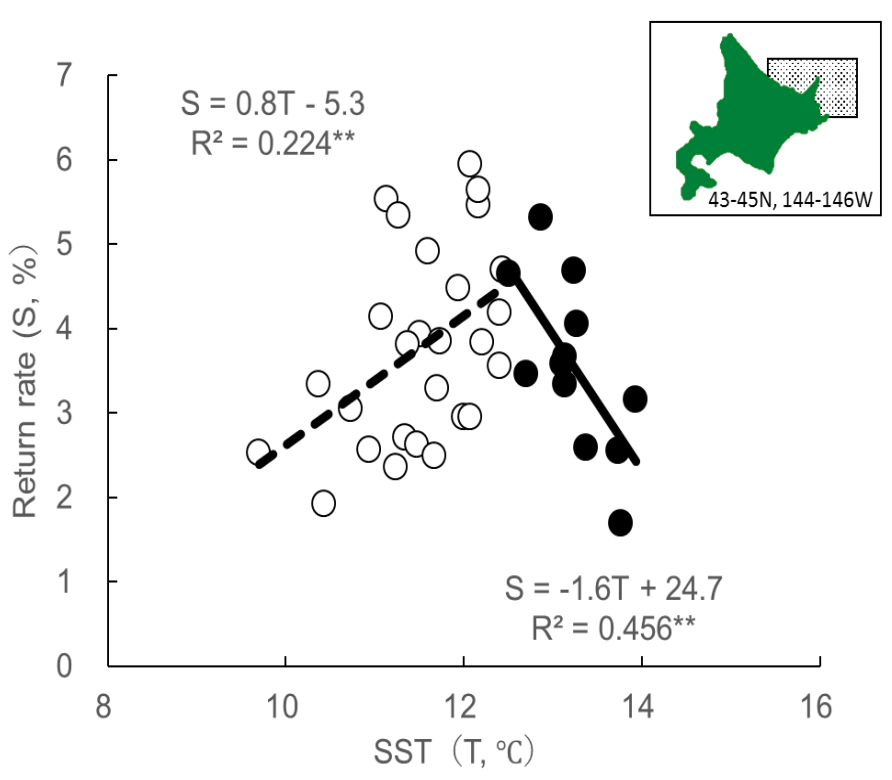

Fig. 6. Relationship between July SST (T) in the Okhotsk Sea Coast and return rate (S) of Hokkaido chum salmon in 1974-2013 brood years.

Within the optimum temperature

- Over the optimum temperature

Figure 5 indicates the temporal change in areas of optimum and adaptable temperatures in July for juvenile chum salmon in the Okhotsk Sea. In the 2010s, the area of optimum temperature (AOT) has quietly departed from Hokkaido Island, even though the AOT was in touch with Hokkaido until the 2000s. The AOT in August gradually decreased and became less than half its size in the 2010s. The relationship between the SST of the southern Okhotsk Sea in July and the return rate (survival rate) of Hokkaido chum salmon has a significant positive correlation within the optimum temperature range $\left(8-12.4^{\circ} \mathrm{C}\right)$, but a negative correlation over the optimum temperature range $(>12.5$ $\left.{ }^{\circ} \mathrm{C}\right)$ (Fig. 6).

Since around 2013, the globally averaged SST has rapidly warmed up and reached its highest level on record. In the record-breaking warming, the contribution of the North Pacific region to the globally averaged SST anomaly has significantly increasedand important effects from some processes at mid- and/or high latitudes are suggested (Urabe et al. 2017).

These results suggest that Hokkaido juvenile chum salmon would miss a migration route to the Okhotsk Sea, decrease their distribution area and their carrying capacity in summer, and decline their survival rate since the 2010s under the global warming effect in the Okhotsk Sea. 


\section{REFERENCES}

Chistyakova, A.L. and A.V. Bugaev. 2016. An assessment of the origin and migration routes of juvenile hatchery Pink and Chum salmon in the basin of the Okhotsk Sea in autumn in 2011-2014. The Researches of the Aquatic Biological Resources of Kamchatka and Northwest Part of the Pacific Ocean 40: 5-23. (In Russian paper with English abstract)

Honda, K., T. Kawakami, K. Suzuki, K. Watanabe, and T. Saito. 2017. Growth rate characteristics of juvenile chum salmon Oncorhynchus keta originating from the Pacific coast of Japan and reaching Konbumori, eastern Hokkaido. Fish. Sci. 83: 987-996.

Ishii, M., A. Shouji, S. Sugimoto, and T. Matsumoto. 2005. Objective analyses of sea-surface temperature and marine meteorological variables for the 20th century using ICOADS and the Kobe Collection. Int. J. Climatol. 25: 865-879.

Kaeriyama, M. 1986. Ecological study on early life of the chum salmon, Oncorhynchus keta (Walbaum). Sci. Rep. Hokkaido Salmon Hatchery 40: 31-92. (In Japanese with English summary)

Kaeriyama, M. 2004. Population ecology of chum salmon. In: the ecology and evolution of salmonids (ed. K. Maekawa), pp. 137-163. Bunichi-sogoshuppan, Tokyo. (In Japanese)

Kaeriyama, M. 2008. Ecosystem-based sustainable conservation and management of Pacific salmon. In: Fisheries for Global Welfare and Environment (eds. K. Tsukamoto, T. Kawamura, T. Takeuchi, T.D. Beard, Jr. and M. J. Kaiser), pp. 371-380. TERRAPUB, Tokyo.

Kaeriyama, M. and H. Ueda. 1998. Life history strategy and migration pattern of juvenile sockeye (Oncorhynchus nerka) and chum salmon $(O$. keta $)$ in Japan: a review. N. Pac. Anadr. Fish Comm. Bull. 1: 163-171. (Available at http://www.npafc.org)

Kaeriyama, M., H. Seo, and Y. Qin. 2014 . Effect of global warming on the life history and population dynamics of Japanese chum salmon. Fis. Sci. 80: 251-260.

Shubin, A.O. and E.G. Akinicheva. 2016. Origin of juvenile chum salmon Oncorhynchus keta (Salmonidae) in the Sea of Okhotsk coastal waters off South Sakhalin. J. Ich. 56: 728-737.

Ueno, Y. and Y. Ishida. 1998. Summer distribution and migration routes of juvenile chum salmon (Oncorhynchus keta) originating from rivers in Japan. Bull. Nat. Res. Ins. Far Seas Fish. 33: 139-147.

Urabe, Y., T. Yasuda, and S. Maeda. 2017. Rapid warming in global sea surface temperature since around 2013. SOLA 13: 25-30.

Urawa, S. 2015. Ocean distribution and migration of Japanese chum salmon. Bull. Fish. Res. Agency 39: 9-19. (In Japanese with English abstract)

Urawa, S. and 19 others. 2016. Forecasting Pacific salmon production in a changing climate: a review of the 20112015 NPAFC Science Plan. N. Pac. Anadr. Fish Comm. Bull. 6: 501-534. (Available at http://www.npafc.org) 